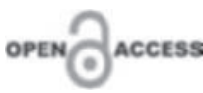

RELATO DE CASO

\title{
Infiltrado Pulmonar Difuso em Paciente Oncológico
}

\author{
Diffuse Pulmonary Infiltrate in Cancer Patient
}

\author{
Laís Cibele Sousa Melo ${ }^{1}$, Natália Carvalho Paim Figueira Santos ${ }^{1}$, Loana Bueno \\ Valença ${ }^{2}$, Ricardo Souza Antenor ${ }^{3}$, José Alves Rocha Filho ${ }^{4}$, Jamocyr Moura Marinho ${ }^{1}$ \\ ${ }^{1}$ Serviço de Pneumologia; ${ }^{2}$ Serviço de Oncologia; ${ }^{3}$ Serviço de Patologia - Laboratório \\ Studart\&Studart; ${ }^{4}$ Serviço de Bioimagem; Hospital Santa Izabel; Salvador, Bahia, Brasil
}

Correspondence addresses: lalacibele@hotmail.com

Received: November 20, 2018

Revised: December 11, 2018

Accepted: January 27, 2019

Published: March 27, 2019

Data Availability Statement: All relevant data are within the paper and its Supporting Information files.

Competing interests: The authors have declared that no competing interests exist.

Copyright

(C) 2019 by Santa Casa

de Misericórdia da Bahia.

All rights reserved.

ISSN: 2526-5563
A toxicidade pulmonar costuma ocorrer em 10\% dos indivíduos submetidos à quimioterapia antineoplásica. $O$ presente caso apresentou paciente do sexo feminino, 77 anos, portadora de neoplasia maligna de Mama (EC II) e comorbidades, em uso de Paclitaxel para a neoplasia, que cursou inicialmente com tênue infiltrado pulmonar bilateral difuso para pneumonia bacteriana severa, e com diagnóstico final de dano alveolar difuso secundário à toxicidade pulmonar pelo Paclitaxel. Este relato de caso demonstra a importância para a toxicidade pulmonar causada por quimioterápicos, quando houver sintomas respiratórios e achados tomográficos que não havia antes do início do tratamento antineoplásico.

Palavras-chave: Quimioterápicos; Toxicidade; Pneumonia.

Pulmonary toxicity usually occurs in $10 \%$ of individuals undergoing antineoplastic chemotherapy. The present case showed a 77-year-old female patient with malignant neoplasm of breast (EC II) and comorbidities, using Paclitaxel for neoplasia. She initially had mild diffuse bilateral pulmonary infiltrate but cursed to severe bacterial pneumonia, with a diagnosis end of diffuse alveolar damage secondary to pulmonary toxicity by Paclitaxel. This case report demonstrates the importance for pulmonary toxicity caused by chemotherapy, since there are respiratory symptoms and tomographic findings that were not present before the start of the antineoplastic treatment.

Keywords: Chemotherapy, Toxicity, Pneumonia.

\section{Introdução}

A toxicidade pulmonar por fármacos é uma reação inflamatória do aparelho respiratório apresentada por alguns indivíduos quando expostos a determinados medicamentos. Os pulmões são alvo de uma variedade de possíveis insultos tóxicos devido não só à sua vasta rede arterial, por onde transita várias vezes por dia toda a volemia do organismo, como também à sua extensa área de superfície de exposição ao meio ambiente. Uma grande variedade de doenças pode acometer as vias aéreas, parênquima pulmonar, mediastino, pleura, vasos e sistema neuromuscular, sendo as pneumonias intersticiais a forma mais comum de apresentação. ${ }^{1}$

Acredita-se que anualmente ocorram cerca de 2 milhões de casos de reações adversas a fármacos nos Estados Unidos, sendo que mais de 380 medicamentos podem causar toxicidade pulmonar, resultando em variadas e inespecíficas formas 
de apresentação clínica, o que acarreta dificuldade diagnóstica. ${ }^{1,2}$ A toxicidade pulmonar costuma ocorrer em 10\% dos indivíduos submetidos à quimioterapia antineoplásica. Assim, os padrões tomográficos e histopatológicos são essenciais para o diagnóstico e tratamento desses indivíduos. ${ }^{3}$

\section{Relato de Caso}

Paciente do sexo feminino, 77 anos, aposentada (trabalhou com Lavradora), portadora de neoplasia maligna de Mama (EC II), hipertensão arterial sistêmica, diabetes mellitus tipo 2, valvopatia (estenose mitral) e doença arterial coronariana com passado de revascularização miocárdica em 2005 , iniciou tratamento quimioterápico em 18/04/18, sendo o $1^{\circ}$ ciclo com Paclitaxel e Bevacizumabepor (suspeita de metástase óssea afastada a posteriori) e os demais, semanalmente, com Paclitaxel. A paciente relatou que desde meados de maio de 2018 passou a cursar com tosse produtiva com expectoração esbranquiçada e dispneia progressiva.

Admitida no Hospital Santa Izabel em 05/07/18, referindo tosse, dispneia e febre (Temperatura axilar: $38,6^{\circ} \mathrm{C}$ ). Exames laboratoriais mostravam hipoxemia na hemogasometria arterial $\left(\mathrm{PO}_{2} 59 \mathrm{mmHg}\right.$ e $\mathrm{SatO}_{2}$ $92 \%$ ) e alteração leucocitária com aumento do número de bastonetes. Radiografia de tórax com tênue infiltrado pulmonar bilateral difuso (Figura 1A). Iniciada antibioticoterapia venosa com ceftriaxone e claritromicina, evoluiu com dessaturação, aumento da dispneia e piora radiográfica, com intensificação do infiltrado pulmonar difuso (Figura 1B), sendo encaminhada para unidade de terapia intensiva em 08/07/18, onde foi iniciada oxigenioterapia sob máscara de venturi a 50\% e escalonado antibiótico para Piperacilina + Tazobactam. Submetida a tomografia de tórax em 09/07/18 (Figura 1C) que mostrou infiltrado difuso em vidro fosco. Em 10/07/ 18, foi avaliada pela Pneumologia, com orientação para manter os antimicrobianos, a metilprednisolona $120 \mathrm{mg} / \mathrm{dia}$ e acrescentar Sulfametoxazol+Trimetoprima. Em 11/07/18, evoluiu com intensificação da dispneia, piora da hipoxemia, quando iniciada a ventilação mecânica, escalonado antibiótico para meropenem e mantidos a
Figura 1. Radiografia de tórax em AP do dia 05/07/ 18 com tênue infiltrado bilateral difuso (A), radiografia de tórax em AP do dia 08/07/18 com piora do infiltrado pulmonar difuso (B) e TC de tórax do dia 09/07/18 com vidro fosco difuso bilateralmente (C).
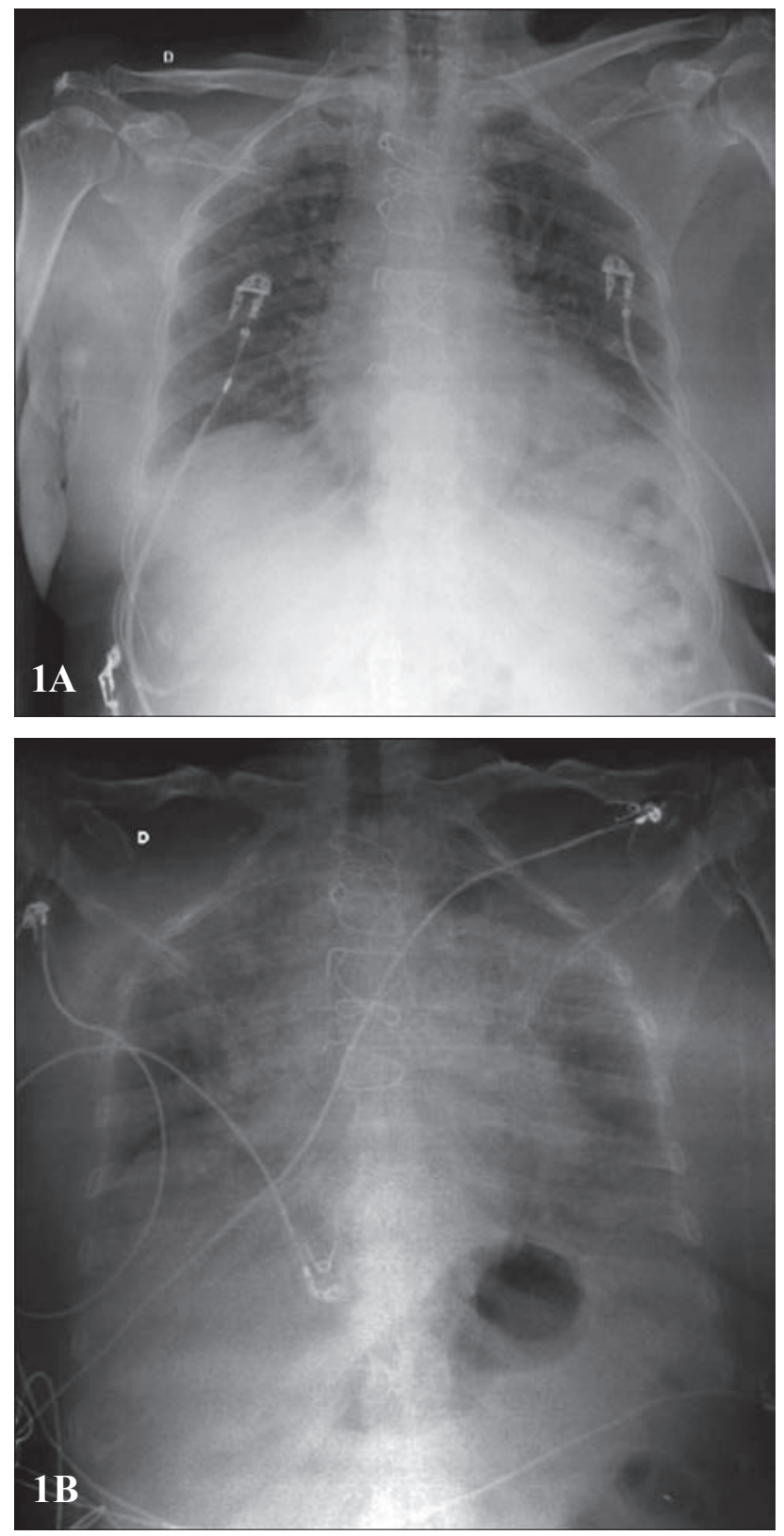

claritromicina e o sulfametoxazol+trimetoprima. Foi encaminhada para realização de biópsia pulmonar cirúrgica, sendo realizadas biópsias em língula e em segmento anterior de lobo superior esquerdo, e iniciada pulsoterapia com metilprednisolona ( $1 \mathrm{~g} / \mathrm{dia}$ por 03 dias). Em 12/07/18, apresentou instabilidade hemodinâmica, sendo diagnosticado infarto sem supra do segmento ST, optando-se por tratamento 


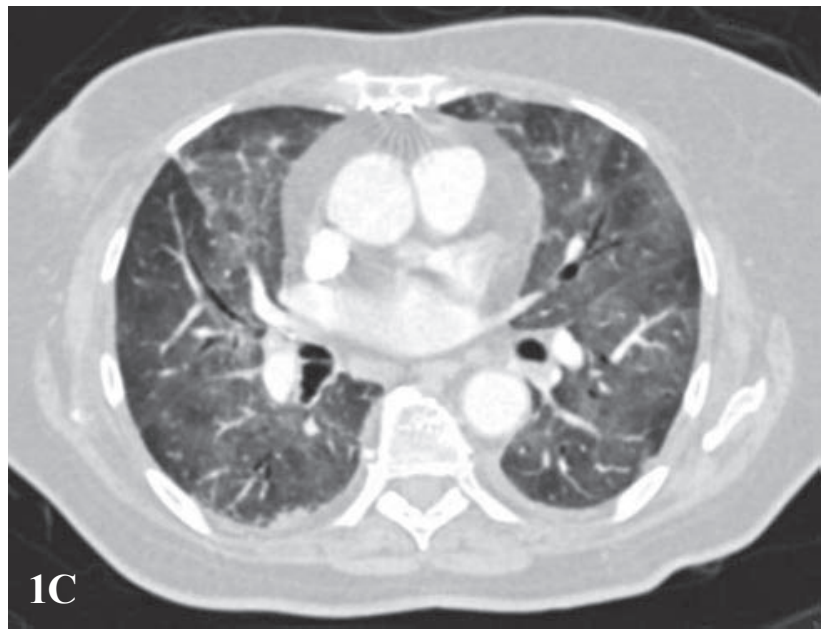

conservador da doença arterial coronariana e modificando a pulsoterapia com metilprednisolona (1g/dia) para prednisona (1mg/kg/dia). Evoluiu com melhora progressiva do quadro clínico, sendo reduzida a dose da prednisona para $40 \mathrm{mg} /$ dia em $15 / 07 / 18$. O resultado do exame anátomopatológico, confirmou o diagnóstico de dano alveolar difuso (Figura 2). A paciente foi extubada em 20/07/ 18 e em 24/07/18 foi iniciado desmame da prednisona. Recebeu alta hospitalar em 09/08/18 apresentando melhora clínica e radiológica, com normalização das trocas gasosas.

\section{Discussão}

Inúmeros medicamentos podem ser deletérios para o sistema respiratório, provocando, principalmente, alterações parenquimatosas como as pneumonias intersticiais, estando os quimioterápicos em posição de destaque, tendo em vista o número crescente de pessoas diagnosticadas com neoplasia que são tratadas com tais drogas. Os principais fatores de risco para a toxicidade pulmonar são: idade $>65$ anos, tabagismo, capacidade pulmonar reduzida e doença pulmonar preexistente. ${ }^{1,4}$

O efeito citotóxico direto contra os pneumócitos tipo 1, as células epiteliais das vias aéreas, o endotélio vascular e a ativação do sistema imune são os mecanismos patogênicos centrais da lesão pulmonar provocada por fármacos. A toxicidade dependerá da dose da medicação e do tempo de uso, mas a reação idiossincrática não é desprezível. ${ }^{4}$ A suspeição de que um determinado fármaco possa ser o agente
Figura 2. HE 200x - Parênquima pulmonar com dado alveolar difuso. (A) membrana hialina, hiperplasia de pneumócitos tipo II e infiltrado inflamatório linfomononucleado e (B) área de condensação pulmonar com membrana hialina e infiltrado inflamatório linfomononucleado.
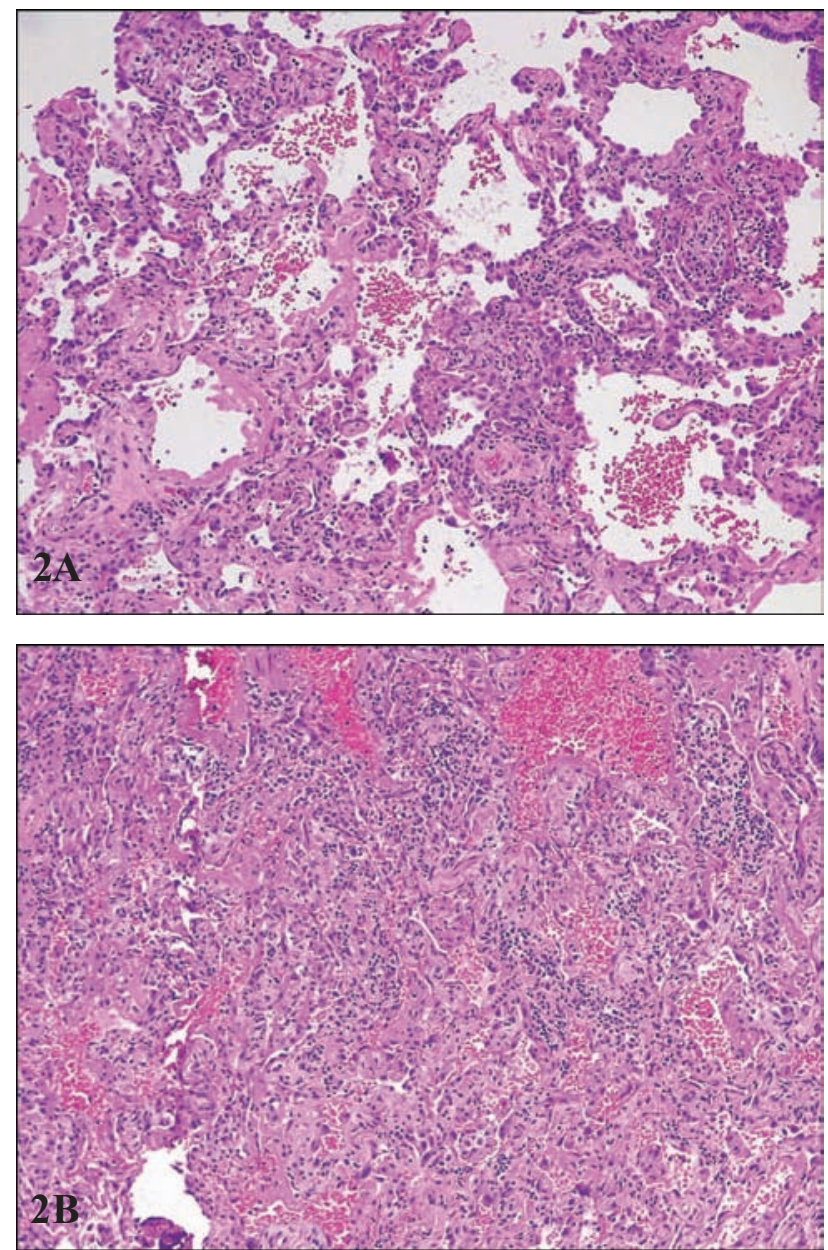

causal da toxicidade baseia-se em dados da literatura, existindo o portal Pneumotox (http:// www.pneumotox.com/) em que podem ser identificadas as possíveis reações adversas pulmonares provocadas pelas medicações.

O diagnóstico da toxicidade pulmonar por fármaco é de exclusão. Há de ser levar em consideração que a maioria dos pacientes em tratamento oncológico são imunosupressos, sendo assim, as infecções pulmonares bacterianas, por germes típicos e atípicos, virais e/ou fúngicos ocupam o primeiro lugar no diagnóstico diferencial de pacientes que se apresentem com insuficiência 
respiratória e achados em exame de imagem. Edema pulmonar e envolvimento pulmonar pela doença subjacente também devem ser lembradas no diagnóstico diferencial. ${ }^{4}$ Outro ponto importante é o nexo de causalidade entre o início do uso da medicação e o surgimento dos sintomas e achados pulmonares tomográficos. ${ }^{2,4}$

A tomografia computadorizada de tórax é o exame não invasivo de maior acurácia diagnóstica nas pneumonias intersticiais difusas e o que guarda mais estreita correlação com os padrões histológicos na toxicidade pulmonar por fármacos. Exames seriados servem não só para avaliar o ritmo de evolução da doença e estabelecer sua gravidade, com impacto na terapia e no prognóstico, como também auxiliam no acompanhamento da resposta terapêutica. Os padrões tomográficos mais comuns são a pneumonia em organização (PO), pneumonite de hipersensibilidade $(\mathrm{PH})$, pneumonia intersticial não específica (PINE), pneumonia intersticial usual (PIU) e dano alveolar difuso (DAD).,

A biópsia pulmonar tanto por método broncoscópico quanto cirúrgico deve ser realizada como forma comprobatória da suspeita clínica e radiológica. Tendo em vista a diversidade de acometimento pulmonar, é recomendável obter amostras de tecido em sítios pulmonares distintos para definir o padrão histológico predominante que melhor se correlacione com os achados tomográficos. ${ }^{1,5}$

O tratamento da toxicidade pulmonar por fármacos se inicia com a suspensão imediata da medicação implicada no evento. Algumas vezes essa decisão é difícil de ser tomada tendo em vista a importância da medicação, sobretudo quando se trata de quimioterapia antineoplásica. Além da suspensão da medicação, na maioria das vezes, há necessidade de uso de corticoide. Casos graves em que há insuficiência respiratória, a pulsoterapia com metilprednisolona tem um papel de extrema importância. Casos mais brandos podem ser tratados com Prednisona por via oral e medidas de suporte. .,6

A paciente relatada teve como diagnóstico final o dano alveolar difuso secundário à toxicidade pulmonar pelo Paclitaxel. A história clínica de dispneia progressiva e tosse, associada aos achados tomográficos de vidro fosco difuso, o achado histopatológico corroborando os achados tomográficos de dano alveolar difuso, a relação temporal entre a exposição à medicação e o surgimento dos sintomas e a excelente reposta ao tratamento com corticoide, demonstrou que se tratava de toxicidade pulmonar pelo quimioterápico.

Esse relato de caso demonstra a importância para a toxicidade pulmonar causada por quimioterápicos, quando houver sintomas respiratórios e achados tomográficos que não havia antes do início do tratamento, tendo em vista o número crescente de pacientes em tratamento oncológico.

\section{Referências}

1. Schwaiblmair M, Behr W, Haeckel T, Markl B, Foerg W, et al. Drug induced interstitial lung disease. The Open Respir Med J. 2012;6:63-74.

2. Camus P, Bonniaud P, Fanton A, Camus C, Baudaun N, et al. Drug - induced and iatrogenic infiltrative lung disease. Clin Chest Med. 2004;25:479-519.

3. Bamias DA, Lyberopoulos P, Dimopoulos MA. Pulmonary toxicity from novel antineoplastic agentes. Ann Oncol. 2006;17:372-9.

4. Kubo K, Azuma A, Kanazawa M, Kameda H, Kusumoto $\mathrm{M}$, et al. Consensus statement for the diagnosis and treatment os drug induced lung injuries. Respir Investig. 2013;51:260-77.

5. Rossi SE, Erasmus JJ, McAdams HP, Sporn TA, Goodman PC. Pulmonary drug toxicity: radiologic and pathologic manifestations. Radiographics 2000;20:124559.

6. Muller NL, White DA, Iang H, Gemma A. Diagnosis and management of drug - associated interstitial lung disease. Br J Cancer. 2004;91(Suppl 2):S24-S30. 